\title{
Surfaces
}

\section{Ernst Behler's "The Contemporary and the Posthumous" Roundtable Discussion}

\section{Hazard Adams, Ernst Behler, Hendrick Birus, Jacques Derrida, Wolfgang Iser, Murray Krieger, Hillis Miller, Ludwig Pfeiffer, Bill Readings, Ching-hsien Wang et Pauline $\mathrm{Yu}$}

Volume 6, 1996

DISCUSSIONS DU PREMIER CONGRÈS INTERNATIONAL SUR LE DISCOURS HUMANISTE

DISCUSSIONS FROM THE FIRST INTERNATIONAL CONFERENCE ON HUMANISTIC DISCOURSE

URI : https://id.erudit.org/iderudit/1064839ar

DOI : https://doi.org/10.7202/1064839ar

Aller au sommaire du numéro

\section{Éditeur(s)}

Les Presses de l’Université de Montréal

\section{ISSN}

\section{8-2492 (imprimé)}

1200-5320 (numérique)

Découvrir la revue

\section{Citer ce document}

Adams, H., Behler, E., Birus, H., Derrida, J., Iser, W., Krieger, M., Miller, H., Pfeiffer, L., Readings, B., Wang, C.-h. \& Yu, P. (1996). Ernst Behler's "The Contemporary and the Posthumous": Roundtable Discussion. Surfaces, 6. https://doi.org/10.7202/1064839ar

\section{Résumé de l'article}

Ces discussions autour du texte de Ernst Behler, " The Contemporary and the Posthumous ", ont eu lieu en avril 1994, dans le cadre du premier Congrès sur le Discours Humaniste. Les communications de cette première réunion du Congrès ont été publiées dans le volume 4 de Surfaces (1994).

Copyright $\odot$ Hazard Adams, Ernst Behler, Hendrik Birus, Jacques Derrida, Wolfgang Iser, Murray Krieger, Hillis Miller, Ludwig Pfeiffer, Bill Readings, Ching-hsien Wang et Pauline Yu, 1996 


\title{
Ernst Behler's "The Contemporary and the Posthumous" \\ Roundtable Discussion
}

\author{
Hazard Adams \\ Ernst Behler \\ Hendrick Birus \\ Jacques Derrida \\ Wolfgang Iser \\ Murray Krieger \\ Hillis Miller \\ Ludwig Pfeiffer \\ Bill Readings \\ Ching-hsien Wang \\ Pauline $\mathrm{Yu}$
}

Surfaces Vol. VI.102 (v.1.0 A - 07/08/1996) - ISSN:

1188-2492

Copyright for texts published in Surfaces remains the property of authors. However, any further publication should be accompanied by an acknowledgement of Surfaces as the place of initial publication.

\begin{abstract}
This roundtable discussion of "The Contemporary and the Posthumous", Ernst Behler's contribution to the first International Conference for Humanistic Discourses, was held in April, 1994. The papers of this first meeting of the ICHD have been published in volume 4 of Surfaces (1994).
\end{abstract}

\section{RÉSUMÉ}

Ces discussions autour du texte de Ernst

Behler, "The Contemporary and the

Posthumous", ont eu lieu en avril 1994, dans le 
cadre du premier Congrès sur le Discours

Humaniste. Les communications de cette première réunion du Congrès ont été publiées dans le volume 4 de Surfaces (1994).

Miller : I now know my job is an easy one, simply to introduce Ernst Behler and let him talk about his paper. But I might begin by saying how much I admire him for the ways in which he's helped me. When I was trying to do something with Nietzsche's rhetoric books, he taught me in five minutes everything I know about the source of these, so I expect now to learn from what he says.

Behler : Well, my approach is different from Murray's paper this morning. I talk very little about translation and cross-cultural activities. Although I hint at them too, I saw my task more in discussing the nature of the humanistic discourse and first discovered a great difficulty in talking about it, if one only considers the three languages we are representing here. The name "humanities," "Geisteswissenschaften," "sciences humaines," always designates something quite different, and it would therefore be very hard to find agreement among ourselves. But my unease about the discussion of the nature of the essence of humanistic discourse is deeper. It's a basic skepticism toward conceptualization in such matters, and also a skepticism toward the selfcongratulatory attitude we experience when we think we have defined something and we have encapsuled something. I refer to Heidegger's Letter on Humanism, where he describes the degradation of the great humanisms of the West in Antiquity, the Middle Ages, the Renaissance, and so on, to an instrument of education, a classroom matter, a cultural concern, culture politics, and culture industry. And we all know about the experience of writing a grant proposal, when we address ourselves to institutions and have to justify endeavors and research projects in the humanities and use inflated terms we use. So, I tried to approach the subject matter and the nature of humanistic discourse from the point of view of its functioning, and looked at how some of the great humanistic discourses of our history came into being Renaissance humanism, but in particular Romanticism. I realized the great confrontation these humanistic discourses constituted with regard to their cultural environment. In other words, I looked more at the functioning of humanistic discourses, which are hardly ever in agreement with the prevailing institutions of their time, and rather appear as critical 
confrontations. They challenge habits, beliefs, canons, and norms, and attempt to replace established rules by new ones. The origin of Romanticism (and I'm thinking here mostly of Early German Romanticism, butalso of French, Italian, English Romanticism) is a good example, if we look at the deep change brought about with regard to the notion of literature, to the function of literature, mimesis, representation, translation, et cetera, and how all this soon extends into a broad range of artistic endeavors in painting, music, philosophy, and theory. So, our image of it is that of a basic change. However, if we ask what effect this change has upon culture (and relate this question to the actual institutions of that time), my impression is that very little changed in regard to their functioning, because this new type of humanism stood in a hostile relationship to its cultural environment, and had only on the long run a discernable impact and influence on institutions. We can think of the salt mine because of Novalis, the law, the madhouse, the university, and the creation of the museum. Influences are noticeable and traceable during the Romantic age, but took place very, very slowly, and mostly not in agreement with the habits and the traditions of the time. The rejection of this new type of humanism was not only limited to the bourgeois world, but included Goethe, even Hegel, if we think of his very sharp opposition to Romanticism. When Romanticism itself became finally institutionalized, at the University of Berlin for example, it soon became a cultural tradition in itself, against which new forms of humanism rebelled and which they tried to undermine. Nietzsche's critique of Humboldt's Berlin University is a late example of it, perhaps the most outspoken, but the best among many other examples throughout the century of this critique. I attempted to give a second example of the distance between humanistic discourse at the time of its articulation and our later understanding, by referring to Nietzsche's theory of language, which for us today, especially for humanistic discourse, is of prime importance. However, at the time when Nietzsche articulated his theory of language, this theory was hardly noticed and actually not recognized until the '60s of our century. Whenever Nietzsche's theory of language was discovered in earlier writings, it was immediately related to certain foundational principles according to which Nietzsche was read at the time: life, will to power, instinctual drives, and survival techniques. The more sophisticated reading of Nietzsche we believe to practice today developed precisely from this topic of a theory of language and the discovery of the importance of rhetoric for Nietzsche's philosophical discourse. I've presented this in my paper which you have read and I don't have to 
repeat it now. The reduction of Nietzsche to vital instincts, and now, the realization that Nietzsche's discourse cannot be reduced to vital instincts and consists of a multiplicity of voices which shape together into that particular type of philosophical discourse we consider to be his particular one, is also something that was realized at a much later time. I also wanted to point out that these changes in our views are combined with changes in the intellectual climate in which we interpret and which are different from the climate in which these discourses originated. It's no longer the atmosphere of absolute knowledge and comprehended history in the style of Hegel. Our tree of Modernism has changed; it has differed from the older one. It's no longer, in terms of philosophy, the line from Hegel, Marx, and Habermas. It is more a line from Romanticism - Schlegel, Novalis, Kierkegaard, Nietzsche, and contemporary representatives. In this realization, humanistic discourse becomes something of a self-questioning, self-critical, auto-critical enterprise, attempting to point out presuppositions, metaphysical assumptions which guide our undertakings, and also questioning desirabilities, what we consider to be desirable. This is what I wanted to contribute to the discussion.

Miller : Thank you. I'll take my privilege as chair to complement a little bit what you've just said by bringing up what seemed to me interesting questions that your paper raises, not by giving any answer to them. One issue was, once again, the importance (that we're going to have to say something about) of historicizing all of this. That is to say, not all of the papers, but many of them, have the instinct of saying, "If you're going to talk about this, you have to talk about it somehow as an historical development." So I think we need to add to Jacques' terms "literature," "translation," and "culture" (that are problematic and might have very different meanings in different cultures), the word "history." Is there a history of Chinese literature in the same way that we think of a history of English or Western literature? Does "history" mean the same thing? Is our instinct, in a way, getting around, avoiding talking abstractly about humanistic discourse by talking historically and saying, well, for the Early Romantics it was a certain way? Is that itself objective, or is that a presupposition which is like certain presuppositions we might have about literature, the literary? So that's one point.

The second thing I found striking in your paper, and very important, was the demonstration, by way of the Early Romantics, of something that might well be generally true. The people that we think are the most important 
and characteristic of the period are precisely the ones that were most in disjunction from the surrounding culture. We imagine, in our own day, that the people that will probably go on being read later on are just the ones now rejected, the theorists that everybody is hostile to, so that you can hardly say that they represent the surrounding ideology. Your example was that, "As soon as one turns to the broader reading public and its literary journals, the reaction against the new discourse as Romanticism is one of unheard of hostility and outrage and actually led to a silencing of this group and its Athenaeum in 1800." It was suppressed. So you can hardly say, as many of my colleagues in cultural studies now would be likely to say, there's a direct relation between the general ideology and these people. We study now cultural context with the assumption there's some kind of relation. My question, assuming what you say is true, would be then what is the relationship? Are Friedrich and August Wilhelm Schlegel and all of these other people simply in a relation of negation to their surrounding culture? Do they have no relationship to it at all, but rather to something indirect? How would you go about studying their relation to the surrounding ideology? And you mentioned Hegel, Hegel's distaste for these people. We know what he thought about Friedrich Schlegel. I was thinking of a citation I saw the other day of Goethe. He wrote, Goethe, on Kleist. He said, this... "With the best will in the world," he said, "this young man has always aroused in me horror and disgust. It's like a body, a body that is infected by some incurable disease." So if we stood back and spoke of that period, we'd say, Goethe, Kleist, they belong to the same period but they don't.

And this is the third point that seemed to me important in what you were saying, and that is, the presupposition that any culture is already heterogeneous in itself. In fact, we had a couple of Goethes. We have a Goethe, your Goethe \{indicating Krieger?\}, the Goethe who believed in world literature, and then the one you cite findicating Behler\}, who spoke of the "'Calcutta nightmares' of transitions into the subhuman and suprahuman," who was just the reverse, suspicious of the non-European, non-Enlightened aspect of Indian literature, of something that couldn't be assimilated, and was, like Hegel, saying these other cultures are untranslatable. That is to say, we can't turn them into human reason. So that's the next point I found interesting and important in your paper: the contrast at this period between the notion of a purely European culture, which was the model for and all others. If it's not understandable by European reason or whatever, the Western mind, if it's 
untranslatable, it's not human, it's subhuman. While at the same time Friedrich Schlegel, you say, was saying "the Asians and Europeans form... one great family and Asia and Europe one indivisible body," a special form of world literature. That's the most important of the points you make.

We may want to talk a little about the formulation you make about Nietzsche on page six (this would be if I was doing a real critique of the paper) about the development into an insistence "on the ambiguity of his statements and the impossibility of ascribing a definitive meaning to them." Probably you would want to refine that a little bit as a formulation about what would now be said. It's not that Nietzsche is not complex, and certainly doesn't fit the paradigm we've been given before about vital will, but that doesn't mean you can't read him, even assign some kind of definitive meaning to what he says. But at any rate, I would say we would have something to say back and forth a little bit about that.

Behler : That is precisely what I wanted to point out, the great discrepancy between our notion of literary history and - well, I cannot say historical reality - some features of the historical context. There is no continuity and homogeneity. This is what I wanted to communicate, although I didn't see my topic as literary history. Then I would have carried this out much further. My topic was humanistic discourse, although my paper looks very much historical. But I considered the historical examples I'm quoting as paradigms, as paradigmatic for my understanding of humanistic discourse as in standing in opposition, in a position of challenge to its time, and not being in agreement with it. The larger question you connected with this was, what are the Romantics then? Are they a completely isolated group from society, suppressed by society? Is there no connection? Of course there is a lot of connection and there is a lot of influence, if one only considers the translation work that they have accomplished - the Shakespeare translation, the Calderon translation, the translation of Italian and Spanish poets. Their translations of dramas were performed in the theatre and exerted their influence upon the language of the time. I believe that the Shakespeare translation of August Wilhelm Schlegel had a deeper impact on the development of the German language of that time than the writings of any other author, including Goethe, because he was the widest read author in Germany. So there are a number of points of connection between this group and their surrounding society. However, when it comes to essential points of their humanistic discourse - the fragment, feminism, et 
cetera - then you have an unbridgeable opposition, and to bridge this opposition took decades. And of course, as soon as these notions became accepted, institutionalized, they were challenged by other forms of humanism, as the University of Berlin shows most directly. I think these are the main points you raised, or have I forgotten something important?

Miller : No, I think that covers it.

Krieger : I want to pursue with Ernst a few of the points that have been made by you and your responses. It does seem to me as if you, while not saying so, could be seen as implying a kind of single heroic narrative structure, with the humanist as the heroic subversive undermining the discourse of a moment, seeking to undermine it, and being flogged for it. But the humanist is somehow prophetic or predictive, and many many decades later, or a century or two later, suddenly the rediscovery that somehow there is something of a reality or a truth, and then will follow the flowering, however much much later, of this beleaguered and dismissed discourse or discourses. And your title itself, of course, suggests: contemporary/no, posthumous/yes. Many many years later after the death comes the re-arising of what is a truer form. A number of things are involved here. One is a notion of interpretation that suggests the original interpretations were faulty, but somehow belatedly we get it right, as if there is a right, and we now have a right Nietzsche or a right Schlegel, instead of the wrong ones that his contemporaries, their contemporaries, dogmatically rejected. I'm just wondering how much you want that as a kind of universal narrative structure, which seems implied here, and of course that is highly Romantic itself. And the other is the question Hillis raised, which I think was a terribly important one, living as we do now at a time when most flourishing theories talk so much about discourse formation and the extent to which our language is not our own, so that we are not subjects who create language, but we're objects that are used by language, by the language of a particular discourse formation, episteme. It seems to me, in contrast to that, that you are suggesting that humanistic discourse, this rare thing of a Nietzsche or a Schlegel, achieves freedom from the formation, and in violence against that formation creates a kind of microformation of its own that stands encapsulated and unappreciated until finally it becomes the formation of everybody much farther on down the line. I'm wondering, so, two things: first the narrative question, the question of this single historical structure you seem to have, the narrative behind your history; but secondly, the question about 
whether you want to give the humanist that much freedom from the discourse formation out of which he grows.

Behler : There's a kind of counter-discours...

Krieger : Yes, every humanist is in the crack.

Behler : Certainly, I see these shortcomings... They are hard to overcome. First of all, with regard to what you call the narrative, the story of an emerging humanism that is first not recognized. People have to suffer and then finally their work becomes victorious. That is, of course, not meant by me in the sense of a landing in a final realization of truth I don't want to say that the Nietzsche interpretation at the turn of the century, or the Heideggerian Nietzsche interpretation, was wrong and now we have the right interpretation of Nietzsche. What I want to say is that these issues are in constant flux, in constant contest, and there is no final station, there is no final realization, there is no final word, they are contested right away when they are articulated.

Krieger : But they make their intervention later; that is, they are performative. Humanist discourse becomes performative in culture belatedly.

Behler : Yes, but not in the sense that it is fully realized. It remains a subject of contest and a subject of reinterpretation. I would say, from this point of view, that humanistic discourses are not entities. They are fluidities, constantly reinterpreted. This also applies to an author like Plato. It's still a contest today of how to read Plato.

Derrida : Here you say process without end.

Behler : Without end, yes. There is no final realization.

Krieger : But do you feel you can universalize to this extent about that sequence? Even if it's open-ended?

Behler : Well, I don't see it in sequential terms. I don't see it in terms of building up toward something. I see it more in forms of disrupture and contest, so that each time has its own approach to it. And this humanistic material is dead if one does not actively reinterpret it every time. It is not a passive, but an active reinterpretation in this sense without any structuralization, and without any formation of an enlarging whole, not even in the sense of dialogical structure. By all means I would like to avoid hermeneutic truth in this sense. The other question you're asking is of 
course much more difficult for me to answer, and that is the question about the subject, the articulating subject, and that there are people at work - Petrarch, Dante, Boccaccio, Novalis, Schlegel - who articulate new ideas and how to see them. Well, I have seen them here as individuals. I think it was also a matter of writing six or eight pages, on which I could not develop a complete analysis of discourse formation.

Krieger : Somewhere they have to get outside for you. Somehow, somewhere they get outside.

Behler : Do you mean outside of the...

Krieger : Of that which is forming them.

Behler : Of that which is forming them. I don't know. I would not necessarily say that, that they are the autonomous...

Krieger : So what is the source of conflict? What is the source of their confrontation while they're in conflict with the reigning...

Behler : If they were entirely the product of their society and of their surroundings, there would be no conflict.

Miller : You say on page seven, "The relationship between humanistic discourse and its cultural milieu is perhaps better described in terms of challenge, confrontation, disruption, and fragmentation of coherence and congruity, also as far as the institutions and especially the 'educational institutions' are concerned." I'm prepared to believe that, but it does seem to me a very strong view of the relationship between Friedrich Schlegel, let's say, and the University of Iena at that time.

Behler : It's a strong formulation that needs critique. I don't know how to perform this critique. I could say, yes, it's overstated, it's not fully meant this way, or... I don't know whether this would satisfy you.

Krieger : I'm not sure I'm complaining. Neither is Hillis.

Miller : Right, I'm not complaining.

Behler : No, but it's a problem, how to articulate this.

Miller : Yes, it is. 
Iser : It could be underpinned by the way in which Hölderlin challenged Fichte at Iena in 1794.

Miller : Right. You couldn't have predicted Hölderlin from the university that he was at. I think that's the point, that it's very difficult to say what is the relationship. If it's a completely empty one, then one is a little troubled by the claim that we have to study cultural milieu at all.

Behler : It's a very very complicated question which I don't believe I can answer. You can ask what motivates Kant to write his Critiques. Is it the society? Or is it Kant? I'm not prepared to give an answer to that question, but I can see the problem.

Krieger : I suppose what I was wondering is, to what extent have some areas in contemporary theory foreclosed this question?

Miller : Yes, well, that's sort of my question too. It's often assumed today that you are willy-nilly the subject (in one way or another, however complicated, but still subject) to the ideology of your surrounding culture, whether you know it or not. And that's very attractive. What's attractive about that is that it gives an explanation. It's explanatory. You say, why was Scott Fitzgerald the way he was? Because he went to Princeton, he came from a certain class, lived at a certain historical moment, and I can then explain Tender is the Night, and so on, on that basis. And that has a very powerful appeal these days, even in sophisticated forms. And you seem to be saying something quite different from that, and I think...

Behler : Well, yes, I would resist a monological, or even a multilogical type of explanation. I would not feel competent or able to say why this originated. I cannot give you sociological reasons either to sufficiently explain this origin.

Krieger : Or to deny that it originated...

Behler : Yes, sure.

Miller : I give you another specific example. When I was at Duke, I saw Fred Jameson, and he was talking about Proust. (Proust is in now, by the way. Everybody's teaching Proust. Jameson's teaching Proust. Kristeva's published a big book on Proust.) 
Wang : And it's been just translated into Chinese.

Krieger : First time?

Wang : First time.

Krieger : That's amazing.

Miller : Anyway, Fred Jameson said that he now knows that the house in 'Combray' that Proust lived in, the aunt's house, was full of memorabilia from North Africa, from the French colonial possessions in North Africa. And for Jameson, that was explanatory somehow. The implication was, "I now have a clue that will allow me to read the three thousand pages of Remembrance of Things Past and explain them in a way that will satisfy my need to put Marcel Proust back in an historic, a class context."

It strikes me as a very good example of what would be the reverse of what you're talking about. There's a very good book by Michael Sprinker on Proust coming out which is a Marxist interpretation. It presupposes that you have to know not only about the Dreyfus case, but also about the class social structure in France during that period. The implication is that that's really what Remembrance of Things Past is about. So, Ludwig, you had a...

Pfeiffer : We may have a tendency of ascribing either some kind of, let's say, homogeneity or heterogeneity or uniformity or conflict quality to the discourses Ernst was talking about. Is it possible (it's a very naive question) that if you look at discourses neither in a traditional history of ideas way, nor in an overly or maybe too much deconstructive way, that we find a different sort of ingredients in humanistic discourses? You had a remark in the earlier pages of your paper that painting and music became "of special importance." And if you just look at some people, not from a kind of literary perspective (to which I think, whether of continuity or of discontinuity, I think we are still a little bit prone and liable to do that), then the image of these people may change in completely different ways. So if you look for instance at John Dennis (English eighteenth century), there is now a big thesis in Germany on the sublime... Suddenly Dennis is made out into a champion of the sublime in the interest of a double aesthetic which goes back much farther than what we normally have imagined it to go back. But then if you look at Dennis as a musical theorist, for instance, you could make him back into a classist, and the same thing, the same kind of switch of 
the direction of humanistic discourse takes with respect to various layers of what we call culture (where I'm assuming that culture is indeed something more or less heterogeneous, heterogeneous but not completely so) might change the picture of these people in a different way from the alternative which we have normally. Are they either against or for or did they judge them in former times incorrectly and are we now in a better position? You didn't elaborate that much on this kind of, let me call it, intermedial perspective, but it seems to be implied in your paper.

Behler : Certainly. If I emphasize the avant-gardism of the people whom I'm quoting here, that has, of course, a rhetorical intent. I challenge something, I challenge the assumption that there are these constants in history. I'm fully aware of the fact that someone like Schlegel or Novalis carries a lot of the tradition along with himself, alone by his language, his Bildung, and his education. These are the constants. I'm emphasizing certain aspects which stick out - but that is of course the rhetorical structure of a paper which wants to show something about the nature of humanistic discourse. That I don't exhaust it thereby I know perfectly well myself. There are of course layers of tradition, layers of constants, in the re-formulation and rearticulation of humanistic discourses throughout the centuries which I did not mention because of shorthand writing.

Pfeiffer : Also I was wondering this morning to what extent we have to make Goethe into a literary man. I mean we're discussing Goethe's concepts of world literature and so forth, but if you read what is considered Goethe's literary writings, of course, read for instance Wilhelm Meister (and this is a literary text admittedly, which seems to be mostly about other things - I mean about the importance of non-literary media for instance, the opera, the puppet theater and so forth). So the positioning of such figures in what we may consider to be a cultural landscape, I think is not necessarily to be identified with either a certain continuity or discontinuity, or a certain conflict or uniformity in some parts of their discourse.

Behler : Yes, that's another aspect of the complexity of intellectual history. Looked at from this perspective, Goethe appears very much on the side of the reactionaries, the traditionalists, which by no means does justice to him. What you just mentioned is of great importance, and relates to the type of literary texts that is very modern and very far away from the traditional. I'm not only thinking of the novel Wilhelm Meister. At 
that time Schiller wrote to him, "How can this novel be poetry, because it's written in prose?" The other example is Hegel. Hegel, from the point of view of Early Romanticism, appears on the side of tradition and reaction. You quoted the example of translation I gave, the argument about the translatability of Bhagavadgita. Hegel of course made great efforts to understand Bhagavadgita. He devoted long periods of his life to this study, but in the end denied the efforts made by the Romantics and Humboldt and talked about the utter strangeness of this work, not adaptable to the Western mind and to the Western type of logos. This sounds from our perspective and from the point of view of our endeavors at this meeting as pretty poor because we want to be cross-cultural and we want to be able to do it. Our sympathy is immediately on the side of Humboldt and Schlegel in this debate, who come forth and say, yes, we can do it, or we can at least try to do it. But on the other hand, it's worthwhile for us to take Hegel's rather negative attitude into account in order to sharpen our sense for the difficulty of such a cross-cultural venture and undertaking. This is always the result of shifting, changing perspectives. I have to argue from some point of view, but if you question me, I like it because it points out to me where I am short or where I am not open enough.

Miller : And you end up with an enormous ninehundred-page book, just for adjudicating the small questions that we ask.

Derrida : Two points. One would be closely related to your paper, and the second one, a little away - just to put the question on our agenda. The first point would have to do with this opposition between contemporary and posthumous. Because I agree with you, I'm wondering whether once you acknowledge that there is a process without end, whether you don't challenge the very distinction between contemporary and posthumous, because this distinction implies that there is such a thing, contemporaneity, contemporaneousness. That is, not only in terms of the synchrony of the contiguation of the moment in which works or authors are contemporary with others, but in the very structure of time, you imply that there is a present which would be contemporary with itself. And I'm wondering whether the structure of... any structure in general, but especially the structure of language or a work of art, a literary work, such a structure, I'm wondering whether it doesn't imply that it's intrinsically non-contemporary with itself first of all, and with contiguation then, if the posthumousness is not part of the structure. What I'm saying here doesn't 
concern your paper only, but every effort to build a synchrony in terms of paradigms, epistèmes, contiguation, a totality in which we assume that the time is not out of joint. And time is out of joint, time is out of joint. That is, finally there is no contemporaneity, and the posthumous is already here. In that case, we would have to transform the problematic and take into account the fact that from the very beginning, posthumousness inhabits the work. Everything is homogeneously posthumous. That would be another way of recovering the synchrony of that. But it's only between many kinds of posthumousness that we have to draw lines, different lines. Now from this point I would jump to another one which is not immediately related to your paper, but indirectly I think related to your paper. Hillis mentioned the way some works were silenced, violently marginalized, or silenced, or repressed. Of course there would be no history without this violence, and there would be no translation without that. When we say it's untranslatable - of course we may say this with respect to the richness of the idiom, and so on and so on - but we could simply say it's because of political censor. It's untranslatable, it shouldn't be translated. And I think it won't be translated, and it won't be published, first of all. So every gesture, such violent gestures - there is censorship, filtering, marginalization, and so on - all ways of decreeing about translatability. It's not translatable. You shouldn't have published this, or you should not have written this, or you should not teach this. When you say, "We won't teach this," it's a way of saying, "It's not translatable" in a certain way, not translatable. So from that point on, I would like to go to what's going on today in our contemporary world. That is, the fact that in many cultures today, there are some writers who are not only censored, unpublished, untranslated - and when you don't translate a novelist, you kill him - but who are effectively, concretely death sentenced. Rushdie would be an example. So what's happening today in the world when so many writers are persecuted because they are writers, because of what they write. This morning we were referring to literature as an institution, so what happens when a culture (I wouldn't associate it with Islam, but with certain nationstates, certain interpretations of Islam, and so on and so on) when they say from their point of view, well, we don't admit, we don't agree that literature exists, that anyone can say anything because it's overall against religion? We don't agree with what is the foundation of the literary institution in Western democracies (a writer may write whatever he wants, in principle, even if there is censorship), we don't accept this institution, we don't accept this institution called literature. And the one who 
writes such or such thing should be killed. Rushdie's not the only example of that sort. Today in Algeria a number of writers, poets, are simply murdered not only because they are poets, but because they speak in a certain way; they are poets who do not obey the state, on the one hand, and do not obey the religious authority, on the other hand. I want just to locate a problem today. I think it has to do with what we're discussing here. It has to do with the institution of literature, its relationship with democracy. In the history of the institution called literature, it is implied, in the Western institution called literature, it is implied that anyone, any citizen must be free to say whatever he wants, whatever he wants, as long as it is fictional, italicize. thus, he is responsible for the contract he signs with the publisher, but he is not as a citizen responsible for what is in the fiction. So there is a link between, let's say, the history of what we call democracy (the freedom of speech, and so on) and the institution called literature. And this set of principles is not universally recognized. So what's happening today if there is a world literature? Should there be also universal agreement on this? And the fact that it's not the case, and that it's not accidentally, the case in Algeria where the example of Salman Rushdie could be multiplied by thousands, means that it's not a tiny problem, it's not a detail. It's a major issue in our world for literature, for the teaching institutions, and so on and so forth. So I think we have to address this problem. We have examples in China, we have examples in India, we have examples in Algeria, we have examples in South Africa, and all over the world.

Miller : The whole world, yes. It's what we used to put opposite the title page of mystery stories that said, "Any resemblance to persons now living or dead is purely coincidental," which was a way of saying, "This is a work of fiction, so you can't hold me responsible for anything that I say in this. I'm only taking my right to pretend to say anything I want." And as Jacques says, there are always limits on that. But that in principle was what was behind the flag burnings, which are parallel. People said, "It's a free country. I can burn the American flag. It's not that I'm not patriotic. I'm a patriotic American. I just want to show that my freedom of, in this case a kind of freedom of speech, allows me even to do that." The violent reaction to that is understandable, but...

Derrida : Just one more point on Salman Rushdie's case. We have founded recently a so-called International Parliament of the Writers, and of course Rushdie is the chair, the absent chair. In this context, I've read a book 
by two Tunesian psychoanalysts writing in French, but knowing the Islam from the inside. And they say, well, when some people want to help Rushdie and to plead for him by saying, "Well, this is a piece of literature. You shouldn't kill someone because...," it's not exactly pertinent. Of course this argument is not unjustified, but Rushdie, at the same time, does in his Satanic Verses, does something particular course. It's a novel, it's a fiction, but it's a very pertinent fiction which changes something, which attacks in a very subversive and efficient way some tradition in the Islam. It's not because it's obscene, and so and so on, but because he really displaces something in his book, and that's why the book is so powerful. So these authors say we should change the strategy. It's not simply a fiction which has to be protected against the power, the state power, against all the religious authorities. It's the freedom to interpret the Islam and to displace something. It's another strategy. And the choice between these two strategies is...

Krieger : Second to some... Second is a political problem.

Derrida : Yes, political... modern political...

Miller : You can say one thing, and that is that at least in Islam, literature is being taken seriously. That is to say, the weakness of the Western theory of literature as the freedom to say anything is the underlying assumption that it doesn't matter.

Derrida : That's why this book, it matters because it touches something, and it demonstrates this very rigorously, that it touches something essential in the tradition, not in the Islam itself, but in the way Islam has been interpreted.

Iser : But this need not necessarily have anything to do with freedom of speech, as there is another definition of literature which pertains to this case. The book is written in 'verse', i.e. in a literary genre which indicates that it is fiction. The literary genre is a fictional sign that invokes a contract between author implying whatever is being said is under the provision of the 'as if'. This technical aspect of literature is sufficient for indicating that what is being said is meant to be taken differently.

Yu : Right. And is that "as if" invocation being made in Islamic tradition, or in the Chinese tradition, or in another tradition? Probably not.

Miller : You don't blame Shakespeare for Iago. But, you know, maybe you do. You say, here is this man who was 
able to think of this, to make up this motiveless malignity - maybe there was something a little suspicious...

Krieger : You know how many Jewish groups have outlawed Merchant of Venice because they didn't want to give...

Miller : Or Huckleberry Finn.

Readings : I guess what I was going to say gets back to Jacques' first remarks about contemporaneity. (I can't look at you from this close together because it would be too simultaneous an instant.) Another way of arriving at that point about the intellectual being non-contemporary seems to me to refer to Aristotle in the Nicomachean Ethics, where he discusses how man may be made unhappy after his death. And it's clear that we're not dealing there with a subject, a creative individual subject in the modernist sense, but with something closer to a name. And I wonder, in some sense, if, regarding the problematic that was being raised about the individual, the relationship doesn't come from the modernist confusion between a name and an autonomous subject. The account of Proust is an alibi for not reading Proust in some very strong sense. That modernist invocation of history as an alibi seems to me something that is very problematic, that is extremely attractive nowadays, and always has been, precisely because it solves the problem that I think Ernst has put his finger on, which is the relationship between political, cultural, and historical determination in an individual consciousness. Now, we used to solve this through standard hagiography, the stories of heroic individuals on the left - Comrade Lenin who would best, as intellectual, know how to synthesize historical determination and individual consciousness. And that is the Marxist version of a certain Enlightenment story about the intellectual. It was precisely the person who can synthesize his - or her, but usually his - capacity to predict, to incarnate the process of history itself as it is nascent. It seems to me that that's what goes, that that model of the intellectual goes along with the presupposition that culture is homogeneous. That is to say, what we have to do is reflect very hard upon what the temporality of thinking can be. I'm not going to talk about Heidegger to Ernst - I leave that to you. But I think Heidegger is an important person in the way in which he argues that thought cannot be contemporary with itself in some sense, and that's a real problem. So that what we seem to be approaching is not so much the difficulty of working out whether intellectuals are contemporary or posthumous, but a recognition that self-criticism is necessary, but that it 
will no longer liberate us from the bounds of historical determination; that is to say, it will not ground a new autonomy. And that seems to me the dangerous kind of seed in the issues you raise, that self-criticism is not simply about getting it right so that we are then free from history, in a sense, and that we have an historical alibi. It's much more problematic and difficult. And there I think we go back to Aristotle, give up thinking of intellectuals as transcendental subjects, and think of them as names in the way we do here.

Behler : I would say the type of self-criticism or autocritique that I have tried to describe includes this reflection on the inability of freeing oneself from social structures. I also would like to respond briefly to Jacques' remarks, which go beyond my paper. They raise central issues for our discussion. The non-presence of the contemporary and the inhibition of the posthumous, of the contemporary structure, is precisely what I wanted to describe in my paper as a particular feature, and maybe a basic nature, of humanistic discourse. The acts you describe - silencing, censorship, persecution, and so on - are important features to be mentioned here, but we should also add to this forgetting, not noticing, limit of attention, et cetera. All this belongs to the same phenomenon and keeps the subject of humanistic discourse in a fluid, developing position. That's how I would respond to you.

Krieger : Yes, I think we can enlarge upon that. You spoke of the censorship decrees by the state, in effect decreeing untranslatability, as you put it. And surely with great violence threatened, or actually imposed - in Algeria, for example. But although it is less violent and much less dramatic and perhaps less important, we can ask about all the other versions of censorship that operate subliminally within our profession, within our society: the journals, the publishers, universities, the censorship that they quietly, perhaps not even consciously, impose at any given moment, of a fashion of one sort or another, of a swing in one direction or another, where suddenly certain kinds of persons, certain kinds of manuscripts are no longer being looked on favorably, etc., etc. As I say, by no means violent, in one sense, but it does a violence to the discourses of a culture. And one of the greatest dangers of this of course is that democracy in any of the usual ways in which we know it cannot prevent this from happening. And so I think there is a large question of how a discourse floats and what the nature of the exclusionary forces within that discourse have to be, and the shifts among those. That brings us back to your point, Ludwig, and that is 
your desire to find something mediating, some mediating third term.

Pfeiffer : Not a third term, but let's say a shifting term, which is not so much tied, connotationally at least, to...

Krieger : To conflict or to conformity. And I wish you could pursue this a little bit, because as you know, one of our great problems is that the history of dispute continually throws up the binary. Even if they're shiftings, they're shifting binaries, shifting conformities, and so on. And yet you're right, I mean I feel you're right, and I want to get inside and between the binaries. But how?

Pfeiffer : Now someone - I thought it was Ernst himself, but I can't find it now, but someone has in his paper expressions like "at a certain distance," or "from a certain distance." That is to say, I think there are manners of dealing with binary oppositions which do not commit you to them in the same way as we think people in the past, before deconstruction, were committed to them (I'm not quite sure whether they were really committed to them, and I'm not sure whether Jacques Derrida really asserts this, but anyway), committed to these binaries really in the way we have made - not me; I don't know who that "we" is now - they have been made up. And I think...

Krieger : Because of Hegel.

Pfeiffer : What do we make of Hegel? Or of anybody? But Hegel is a case in point. I mean, on the one hand he is the reactionary - in some sense reactionary - German philosopher. He's an obscurantist for many people, hard to understand. But then the question is, how important is, for instance, this notion of understanding Hegel or not understanding Hegel? If you look at some of his writings, he himself is an advocate of not understanding, at least of non-understanding all the time in a certain way. For me it was hard to reconcile the Hegel picture I've been used to with the Hegel I got in the aesthetics, I mean in the aesthetic theory, as it is transmitted. To us of course that's another question. I mean, what are the mechanisms also in terms of some kind of involuntary censorship, sometimes voluntary censorship, of Hegelian texts? But anyway it's still hard for me to reconcile some 'philosophical' parts of Hegel with the way Hegel talks about music, for instance (since Ernst brought that up). And once you take into account something which is not so much tied into our discourse, into our discursive tendencies, then I think it opens up at least a space for - 
I'm not sure whether that's Wolfgang Iser's notion of negotiation, but for me it would be of a negotiation of these oppositions, which I think is different, without my knowing what the result of that might be. It's not so important...

Krieger : As long as it isn't reconciliation...

Pfeiffer : So for instance, when Hegel favors the Italian opera, then you suddenly see a side to him which seems very remote from our normal notions of understanding, conceptual development, aesthetic behavior, and so forth. That's what I was driving at. Must this shifting be binary? I don't think if we say even the shifting must be binary, we still have an exegetical frame as it has been provided by structuralists. Now if we switch to someone like Rosenzweig, then do we have a differential? It's a constantly shifting sort of unfolding something into different profiles which continually shade into one another - that's not binarism anymore. So in that sense, I mean, there are other ways to talk about shifting, if one wants to conceptualize that, none going back to the structuralist frame. And so I keep asking myself in that connection too, I mean, do we constantly have on the one hand, let's say, normative principles, or whatever? And then we try to historicize them. But that's also binarism.

Iser : I should like to switch to a different example. The Romanian linguist Coseriu modified the de Saussurean opposition of langue and parole by introducing what he called 'a middle norm'. The language system (langue) can never be fully activated. Therefore the 'middle norm' functions as a historically conditioned frame providing guidelines for the way in which the language system is or can de used. The frames are restrictive up to a point and consequently subject to change. Still, this triadic relationship between langue - middle norm - parole allows for pinpointing what is usually historized when a form of discourse tends to become obsolete. We have to jettison the binary opposition, because when discourses are being critiqued it is more often than not that the frame provided by the 'middle norm' comes under attack. This makes me ask my question. When you say, "Humanistic discourses probably function best in their cultural context when they are interventive...", I keep wondering what the intervention aims at or wants to interfere with.

Krieger : Well yes, the posthumous Nietzsche becomes interventive. 
Readings : The one reserve I just sort of mark around, Wolfgang, is your notion of exegetical frames. I'm not familiar with the Rumanian linguist to whom you refer, but I would run the argument through Bakhtin. (I'm thinking of Bakhtin because I've not called in this week to find out who actually wrote Marxism and the Philosophy of Language.) In Bakhtin the problem becomes how unified and how homogeneous is an exegetical frame? The problem is related to the horizon of expectation, and then you're back historicizing once more, it seems to me. And it's very difficult - and again, I'm thinking that what Ernst was saying in the context of fragmentation is very very important there. You mustn't apply a notion of the exegetical frame that eventually closes the frame.

Krieger : You worry about the word "frame" as enclosing. It may not be a good metaphor. It may not be a good metaphor for that reason.

Iser : Does a frame necessarily imply closure or can it not equally mean guidance?

Miller : Well, it's associated with idioms, as you know, like "I was framed." I didn't really do it, but I was set up by circumstances to appear to have done it. And there's no escape. All of a sudden, I'm arrested for a crime I didn't commit, and I defend myself by saying, "I was framed."

Krieger : And all the evidence is there.

Iser : Still, the frame means the range for guidance is limited and in the sense of the middle norm subject to a historical conditioning. Therefore, you can again historicize this kind of guidance provided by it.

Miller : But we also say "frame of reference," which would be another English idiom.

Iser : Yes, and if you take into consideration what Goodman has to say about frames of reference which keep changing, then the notion of frame as I am inclined to use it can be substantiated. The frames of reference in the Goodmanian sense, are highly mobile; they are not just something that is fixed.

Readings : This gets back to the question of culture, because another thing that has to be said about some of the arguments in cultural studies is precisely about the notion of "the culture" as the artist - I'm thinking of Ruth Benedict's Patterns of Culture - where there's an 
implication that the cultural frame has done everything. And what's quite interesting about that argument is that then it turns out that that notion of culture is actually founded on a kind of romantic notion of the artist; instead of the artist we appeal to the culture, but we appeal to the culture as if it were an artist to explain it. That is just imperialism all over again. It's like the Jesuits, who accused the early Native Americans of playing all the time because their work didn't look like work. And we simply transvalue that and say, every Hopi basket weaver is performing a cultural function, and we describe every action in a culture in terms of this homogenized version of the culture which is supposed to produce it. So you can never be an unhappy member of a culture. That kind of ethnographical move seems to me very dangerous, and to be another way in which there's an attempt to make "thought" contemporaneous with itself. There's an attempt to make it somehow possible to slice out, fix, and establish a langue.

Iser : I don't say that.

Readings : No, no, no. I'm just trying to spin off it toward something like a recognition that the problem with humanistic discourse - I'm not quite sure what discourse means there, but let's say "the humanities" - is that their central axis has been a notion of culture as the synthesizing of symbolic life into something that can be both an object of study and a process to be taught. That's at least since the eighteenth century, you know, when the word "culture" takes on its function. And I think that part of the problem is that - Murray, you used the phrase "we're living at a time" - the possibility of saying "we are living now" implies a historical, temporal structure to thinking founded on the notion of culture. What I think to be more generally worrying is that the notion of that kind of cultural unity has disappeared, and we've presupposed any culture to be heterogeneous, and at some point I want to say, that may well undermine the term "culture," in some sense. That may well require us to trace a rather difficult and dangerous etymology. I mean, I'm not sort of giving up the argument to the right wing - you know, either culture is one or it is not. I'm just saying that I think that the kinds of claims we've made about culture seem to me ultimately to be more than a question of just shifting the orientation of what we say about culture.

Birus : Is that historically correct when you say all culture has always the aspect of implementation? For instance, Roman culture: there was the implementation of Greek values, of Greek ways of behavior. And then 
that process described by Ernst Robert Curtius in his book European Literature and the Latin Middle Ages. This evolution of the vernacular languages in connection with the sacred language, or the language of the intellectuals, Latin. And I think this double orientation can be used for the definition of humanist discourse. The relative homogeneity of culture, and also of humanist discourse is a product of balance and of finding an equilibrium between heterogeneous components in the orientation on different values. Thus I would say - this is part of my argument tomorrow, and I will not anticipate it here - that the word "humanist" always has to do with this double orientation, that it marks a standard; who doesn't fill the standard is excluded from the discourse. But on the other hand, it is a standard that comes in some respect from outside, and it would be good to come as close as possible. And this double orientation - I think it could also explain the problem of being contemporaneous, and being posthumous at the same moment for humanist discourse.

Iser : If I were to schematize what you are saying, the humanistic discourse you have in mind is atranslatio studii.

Birus : In one respect, yes. And in one respect it is what is natural for a human being, in the full sense of the word.

Iser : Then the question arises: to what extent is the kind of discourse that Ernst has presented something different from the one we call translatio studii?

Birus : There is a difference, naturally.

Iser : The question of discourse is on the table again?

Birus : My point was only to say: in humanist discourses (as I know them in the West), there is on the one hand this orientation towards what is human, what is common for all human beings over the frontiers, and at the same time there is always a ritual of exclusion, maybe of beings who are not yet real human beings, not well educated, and so on. So the translatio studii is only one version of this double descriptive and prescriptive aspect of all humanist discourses. And we can closely examine it tomorrow.

Iser : The duality which you seem to be advocating was subject to major historic shifts due to the fact that the understanding of what is 'human' or human nature has changed. This duality may still have been entertained in 
the Renaissance, but since the advent of Romanticism all hard and fast statements regarding human nature have been toppled. What has been excluded from the definitions provided was made to strike back at the definitions. Thus duality became a concept that was subversively applied.

Krieger : I think we do the Renaissance an injustice, and you can find the same toppling, the same duality in every moment. The secular and the theological...

Iser : Still, the Renaissance was much more committed to exploring what the human situation is like. The reception of Theophrastus highlighted a growing interest into the diversity of human nature.

Derrida : I feel there is a tension in the concept, in the history of literature, between two [tendencies]. One would associate literature as in its historical forms with humanism. There is a philosophy, metaphysics, which not only defines the essence of man but puts this essence at the top of everything, as the measure of everything. This humanism has to do with a secularization at the same time as with a desecularization. Although there is, of course, a sacredness in literature, nevertheless there will be a movement of secularization - humanism, secularization, democratization, at the same time. This will be connected with humanism, the sacred with humanism. That is, the universality of a human being, world have to do with a human essence. And from that point of view, if I go back to the question of Salman Rushdie, then it's only a theocratic state which sentenced to death a writer, and so on and so forth. But on the other hand, literature as a modern phenomenon would have another tendency, namely, to put in question this humanism, that is, to open something, to push the secularization so far that it would subvert what the humanism has justified, had kept as a..., as the theology which it has kept in itself, secretly or openly. So in that case, literature would be not anti-humanist, but ahumanist in its movement. And I think these two are I'm oversimplifying, of course - but I think this tension is at work in modern or postmodern literature. On the one had, it's politically allied with democracy, humanism, a democracy which is associated with humanism, and so on and so forth. On the other hand, perhaps associated with another kind of democracy, what I call democracy to come, and not simply linked with this kind of humanism and auto-theology, to use this stereotype (with Heidegger). There is an auto-theological concept of literature and a non-auto-theological concept of literature, which would not be linked to humanism. 
Miller : I was going to say, Ernst, another sentence in your paper seems important to me. That is the one on page five, at the top, where you say, "the critical theory or the philosophy or the humanistic discourse of Early Romanticism remained a matter of contention for a long time and was perhaps not recognized in all its radicalness until very recently." I take it what you're saying here (and it goes along with the conversation we've just been now having) was that Early Romanticism is a real new beginning. That is to say, it's radical in the sense that it does form a break; it forms the beginning of something - "root" - out of which something grows, which takes a while to be assimilated, and so on. That would be a view of cultural history that we all find very attractive: that is to say that it's punctuated not only by discontinuities or disruptions, but also by something considerably more positive than that, namely a kind of beginning in which something radical, that's really radical and hadn't happened before, which bears fruit later on, which may lie in wait for a long time, which is not contemporary with itself, which is always out of time, and so on. And that this happens... that we can locate the times retrospectively in which this occurs - in the Renaissance, Greece. Early Romanticism is a moment of that sort. That's a very interesting notion, I think. I'm still brooding about my problem concerning the relationship between that kind of event, a radical new event, and its link to the surrounding culture. It could only have happened in Germany, could perhaps only have happened in the German language, et cetera, et cetera, but nevertheless is radical in the sense of being something really new that takes a long time to assimilate, is assimilated very differently. Nietzsche, in your picture here (you say fragmentary story, you need the eight hundred pages to tell the whole story), Nietzsche is another such event. That is to say, for you, and for me too, something happens with Nietzsche that takes quite a while to discover its radicalness because it's suppressed in various ways by things that the author himself says. Just as, you know this immensely better than I, there's more than one Friedrich Schlegel even on that point of allegory and symbolism. So Schlegel is not homogeneous with himself; there's a later, much more conservative Friedrich Schlegel, et cetera.

Behler : This is what I wanted to point out, and that's why I have chosen this example. I said originally, this is paradigmatic. I did not want to give you a paper on Early German Romanticism. That was not my purpose. My purpose was to convey something about the nature of humanistic discourse. But simultaneously I speak about 
Early Romaticism, and this is the reference point, for us a very important one as far as modernism and postmodernism is concerned. This is a radical break at the end of the eighteenth century, during a period of time which covers hardly more than five years. What took place was a basic break with the model of mimesis and a shift in the conception of totality. Totality is not given up, but seen as a fragmented totality. Fragment is not just seen as a fragment, fragment is something of a larger whole. There is a shift in the view of the world. The style of writing changes. The difference between philosophy and literature is more and more suspended. It is very hard to draw a dividing line between Transcendental Idealism and Early Romanticism. I also wanted to suggest that a different canon of our tradition originates, a canon that goes this way: Romanticism, Kierkegaard, Nietzsche - a canon that challenges the Hegelian canon.

Birus : I think the most interesting thing then is how did this radical break, this radical beginning happen? And the other aspect is that if you look close at the literary production of Early Romantics, you find nearly no new element. You look in terms of meter: nearly all characteristics of Early Romantic poetry you can find in Goethe. If you look on this inclination for the Middle Ages and for folk poetry, you can find all these things before. In some respect, this beginning was not a radical beginning in the sense of having some things in their own, a kind of reshaping and new ordering of well known elements. Friedrich Schlegel (Athenäum, Fragment 216) was wonderful in formulating the three main tendencies of that age: French Revolution, Fichte's Wissenschaftslehre, and Goethe's Wilhelm Meister, i.e. prose that is as artistic as poetry. These three tendencies were the new beginning in the way of reordering. And maybe it is not only the case for the Early Romanticism, but also for humanist discourses, that they are not in that strong sense inventive, but reordering.

Behler : That is very well my intention, and I would go further and deny the innovative character of these three events: the French Revolution, Fichte, and Goethe. Even these events are bound to the tradition. This is what Ludwig brought up earlier and what we had discussed with regard to the ancients and the moderns. It is not so that in this debate the moderns take over and win. The basic ingredient, the basic feature of humanistic discourse is not innovation, it's interrelationship. 
Krieger : You know I could make, given time, almost a very similar analysis of the new beginnings of the Renaissance.

Readings : I would just like to point out that if you try to teach a serious comparatist course on the Renaissance, you discover that the Renaissance never "occurred." I mean if Burckhardt is essential, you cannot think the Renaissance... When does the Renaissance begin? It begins in Germany, in Switzerland. And that's where the Renaissance occurs, when Burckhardt says, Here are the properties of Renaissance art, and they also happen to be the properties of historical consciousness. And there is no event that is called the Renaissance. There is, however, a radical inauguration of the possibility of historical consciousness as a rebirth rather than as an origin. And that seems to me to be a very complex dispositif, and one which Romanticism in some strong sense repeats, and one that we aren't yet quite out of. I mean, I like in my optimistic moments to think that postmodernism is an attempt to think our way around the model of lost origin, renewal through translation, resynthesis, cultural flowering. And when Hillis brings up the radical or inaugural event, I would say that is what actually challenges that model, that Renaissance or German Romantic historical dispositif, apparatus, the historical structuring.

Behler : But we still need Burckhardt's model of the Renaissance in order to deconstruct it. These are the models of formation of humanistic discourse.

Readings : Any book on the Renaissance will tell you, it began sooner than you think. That's the rule of writing a book on the Renaissance. Unless you write a book on the Renaissance that says, no, it began just when you always thought it did. As soon as we identify any aspect, then we can move it back, and so on and so on. And then I would say, Burckhardt invented the Renaissance. Let's be honest about it.

Birus : But to say it in a paradoxical way, you could say, the Renaissance as humanism took place in nineteenth century.

Readings : That's exactly what I say.

Iser : What does that mean are there only repetitions or always new beginnings? However, there is a different way of looking at it. If a certain type of discourse as the one current in the Renaissance comes to an end, it 
nevertheless imprints itself - albeit negatively - on what is to follow. It may turn out to be a blind alley, yet it conditions up to a point the new type of discourse. Such a conditioning could neither be inferred nor causally derived from the one that is on the wane. That is a relationship deserving attention when one is inclined to opt either for repetitions or new beginnings.

Behler : Another feature of this posthumousness is that if you try to date, and want to be precise, let's say about modernism - modernism is perhaps the best example you date it earlier and earlier. You are driven back. It's very dramatic. For instance, when Nietzsche or Schlegel want to find the origin of modernism, they find it earlier and earlier. In the end, it is Euripides.

Birus : It's like Thomas Mann's Joseph and His Brothers.

Behler : Or Socrates. These are basic features of Humanistic discourse, the relationship to the past, and the relationship to the future, which are essential and...

Readings : I would say that the infinite regress is the vanishing point in perspectival painting, and that the reason why Burckhardt is so important is that he understands the relationship between what he calls the Renaissance invention of perspective and the notion of historical perspective. And he founds the possibility of cultural history, of humanistic history, upon a model of perspective that he finds in his version of Renaissance painting. The point about action is that you cannot take a perspective on it. This is the problem. And then I would say, well, so the perspectival metaphor as the rule of the history of the humanities is being called into question. And that seems to me to be the non-contemporary challenge - the problem that we're having, because we're actually sort of being quite honest about saying things today that we probably wouldn't dare say in front of our students because it upsets them too much: that you cannot date with any certainty the origin of an event, but that you cannot, on the other hand, think without that apparatus. It's a paradoxical one. It's resulted in a lot of silly things being said about deconstruction, because you know if you say, for example, you can't be certain about dates (which I take to be one of the things that deconstructors tend to say), then people say, well you're a nihilist, or something like that. And then if you actually ask anyone, they'll admit quite happily that this is a serious problem.

Miller : You can't know the dates of the Civil War. There's a marvelous example of that inability (I'm a 
literary person myself), a kind of paradigmatic allegory of this in a novel by Anthony Trollope called Ayala's Angel. Ayala thinks only an angel come down from heaven would be good enough for her. And she meets a man with red hair, kind of awkward, in the beginning of the novel, named Jonathan Stubbs. And she says to herself (this the narrator tells us), this is not my angel. Six hundred pages later, she accepts Jonathan Stubbs. He quite reasonably asks, "And when did you first fall in love with me?" She says, "I think it was when I first met you." Then you say, I must have misread the novel, so you go back to the beginning, and you find no source for this. On the other hand, she's telling the truth. Like the beginning of the Renaissance.

Yu : There was a beginning ...

Miller : She didn't know it, we don't know it, the narrator didn't know it...

Yu : But it happened.

Miller : ... certainly Jonathan Stubbs didn't know it. And then you read the whole six hundred pages in between and look for the place where she moved from not being in love with Jonathan Stubbs and being in love with him, you can't find it. I was going however to ask you a serious question about event, and how you've been lecturing about what Heidegger says in his book on the event.

Behler : Yes.

Miller : Is Early Romanticism an event in the Heideggerian sense? That is to say, does the concept of event in Heidegger's sense of it (whether there, in his book on the event, or in Sein und Zeit or elsewhere) help us at all as a name for a kind of non-contemporaneity, like the event of Ayala falling in love with Jonathan?

Behler : No. Romanticism does not fit the particular feature of the notion of the event. The event is in our understanding an occurrence, which arrives at a certain moment. This is an event, when you fall into the abyss, when you are reaching out for dwelling, when you are on the way to an event, but Romantisim is different in the last analysis. No, Romanticism is not in this sense an event. There's also what we have been trying to do through our analysis of the origins of Romanticism and the Renaissance. We could say we have tried to deconstruct such a strong beginning, we have predated it, moved it back or forward, related it to us, and thereby 
taken out the uniqueness of it, as if it were a momentary happening...

Iser : This ties in, at least partially, with Whitehead's definition of the event as "an occurrence that exceeds referentiality."

Behler : Right.

Miller : So the event of Nietzsche's lectures on rhetoric was not for those two or three students who heard them, but some good many years later.

Behler : This is of course wrong in Lacoue-Labarthe, who construes this reading of classical rhetoric as a moment in Nietzsche's development when he turned to a new concept of language. He also gives this essay, the title "The Detour," as if what Nietzsche had done before, The Birth of Tragedy, had been a detour; Nietzsche could have cut through much faster, if he had only read the texts on rhetoric earlier. He would have had his metaphorical notion of language much quicker. Well, this is really the construction of an event. Lacoue-Labarthe's essay is enormously valuable, I don't want to minimize it in any way. But here you have the notions of event and occurrence in a specific way.

Miller : It would also be an example of the way it's constructed out of pieces that are already there. As you taught me, those lectures on rhetoric are almost entirely cribbed. All the examples are stolen, everything is stolen. But the question was whether the term "event," in the Heideggerian sense, would be relevant to our discussion here.

Behler : Let me rephrase this. We need the term "event," we have the desire to date, to be precise, and we also devote all of our scholarship to the determination of an event. But then there is this double reflection which tells us, this is necessary, but simultaneously impossible.

Miller : Is this a place where translation comes back again? What's the German word for "event" for Heidegger? Ereignis?

Behler : Yes.

Miller : It's not really quite translated by "event," is it?

Iser : Ereignis is more the English 'event'. 
Behler : Yes. It's also more processural; it's not concluded, does not come to a final result. It's in process.

Miller : So the point I'm making is that, it's not that it's untranslatable. You can translate Ereignis, but it isn't quite the same. It's...

Behler : That's what we realize when we deal with such terms.

Krieger : How about "happening"?

Behler : "Happening" would be better, yes.

Yu : In all of the senses of the...

Readings : The 'sixties sense too.

Birus : The etymological connection is that which you can see with your eyes, and these connotations all are important.

Miller : And nothing of that is there in the word "event" or in the word "happening," either one. So the associations with other German words that are connected like sich, eignen, Eignung, he... not only the etymological ones, but other connected ones, are lost in translation. It's not that you can't translate it, but that something funny "happens" when you try to do it.

Krieger : That's going back to Wolfgang: the translation empowers your sense of the untranslatable.

Miller : That's right.

Iser : You remember, Hillis, we once tried, I think, successfully to correct the Heideggerian term 'gegenwendigkeit' in the essay on "Ursprung des Kunstwerks", which in English is rendered by "contradiction." "Dual countering" - that's what we came up with and this at least grasps something of what 'gegenwendigkeit' in this particular context implies.

Miller : I find, much more than with French, the juxtaposition of English and German languages tremendously exciting and productive intellectually, just because they're so different. I mean you would think English is supposed to be a Germanic language... with a few Romance words mixed in. But as a non-German speaker and reader, it seems to me a much more strange language than French or Italian or any other Romance 
language - and wonderfully and productively so. So that it's like entering another world. There are things you can think in German that are very hard to think in English or French.

Wang : This reminds me of what you said this morning about the translations into Chinese, Korean, Japanese, of the Sanskrit texts. There's really a problem. I forgot to mention that because, for example, in Buddhist scripture, the texts translated into Chinese show so many words, as if in transliteration, that are impossible to translate. Actually that enriched Chinese language too with all the new things. And if we read Medieval poetry, earlier poetry, we see all those terms. And the Chinese idea is that everything should be contemporary. We just try to say what they have said and then in another form. However, so if you go into a poem written in the tenth century, for example, and there's a term, and you go to the older text to find the allusion or whatever, you won't be able to find those, because these are the translated Sanskrit terms. And I was going to ask, when you talk about the contemporary and also about the posthumous, why don't you have any coverage about the past in relation to the two? Because it seems to me that in Chinese humanism, in the Chinese tradition, it's probably more important about the past and about the future, and the contemporary is often of a very loose nature, a soft structure there.

Behler : This is only because of the rhetorical form in which my paper is presented. But I think during the discussion it came out that I don't have any fixed point here or there, and that everything is moveable in all directions. What I want to say is not directly related to your question, but to the general problem that was discussed earlier: translatability of Asian texts. That was - I mentioned it only very briefly in my paper - a hot issue at the time of Romanticism, and I quote Hegel and Goethe - Goethe is not an important point here - but the position of Hegel is. Hegel says that the Bhagavadgita is not translatable because of the different structure of the logos. It cannot be translated. On the one hand, we have the impossibility of translation or untranslatability maintained by a great philosopher who, as I said earlier, made great efforts himself to work himself into this different system of language and philosophy. On the other hand, we have practitioners like Humboldt and August Wilhelm Schlegel, who actually translated. This controversy became a big debate in the French periodical Journal Asiatique at the time. It was not Schlegel, but Humboldt who stood up against Hegel and 
maintained the translatability of the text. Of course, Humboldt was well aware of his shortcomings, his failures, that he couldn't render all the things that you have mentioned. But translation still is a task that one undertakes and tries to carry out at one's best.

Miller : There was one moment or phrase or sentence in your paper that I thought was very important. It was because Humboldt won here...

Behler : Yes.

Miller : ... that there were established all of these chairs...

Behler: That's true, yes.

Miller : ... and that the tradition in Germany of the study of those Oriental languages, which remains as a discipline, and really I suppose still the model for the discipline of the study of Indian, or Chinese, or Japanese, even in all Western universities. So that it was an historic moment of the institution. It depended on the assumption that you could get some results by doing this.

Krieger : How much of Said's orientalism figures into that, by the way?

Miller : Yes, sure. Because Humboldt's claim was that it was reducible to the Western logos. That is to say, that you could write sentences which were grammatical and logical in German, or English, or whatever, that corresponded in some way to the thinking of Sanskrit, or Japanese, or Chinese. And not to claim that would be to say there's no point having this professor because the professor is not going to have anything to do.

Yu : You can't get there from here.

Krieger : So the issue between Humboldt and Hegel was: is it or is it not reducible to our logos?

Miller : That's right, that's right. It would be just like people now who say women's studies is not a discipline, there's no substance to women's studies. Therefore, to have a professor of women's studies is a total absurdity. Or the introduction of any other new discipline.

Iser : But Edward Said made it absurd from another angle, namely that professors of Oriental studies created Western imperialism. 
Miller : That's right. Well, the question, I think our general question is how we can imagine this crosscultural translation without, without that... imperial assumption. That is to say, how you can have something which is an ongoing interchange without having some dominant culture... some hierarchy. And Jacques's questions about the concept of literature, the concept of translation, and so on, are crucial here.

Iser : We have to make all these concepts slide into something else in order to prevent them from establishing clear-cut hierarchies.

Miller : Right. And it's hard for us to do it at our age, in our time... I'm not going to make any attempt to summarize, but to say we've had, perhaps, an event... I don't know; you never know that you've had an event until maybe fifty years later, so I wouldn't dare to say...

Accueil Surfaces | Table des matières | Recherche Surfaces Home Page | Table of Contents | Search

PUM | Livres | Revues | Publications électroniques | Vente et distribution 